\title{
Quantified sea-bed dynamics of the Netherlands Continental Shelf and the Wadden Sea: a morphological and sedimentological approach
}

Thaiënne VAN DIJK, Netherlands

Deltares, Department of Applied Geology and Geophysics

University of Twente, Department of Water Engineering and Management

Sytze VAN HETEREN, Netherlands

TNO, Geological Survey of the Netherlands

Marco KLEUSKENS, Netherlands

Alten PTS

Laura VONHÖGEN-PEETERS, Pieter DOORNENBAL, Ad VAN DER SPEK, Bob HOOGENDOORN, Netherlands

Deltares, Department of Applied Geology and Geophysics

Leendert DORST, Netherlands

Hydrographic Service, Royal Netherlands Navy

David RODRIGUEZ AGUI LERA, Netherlands

Deltares, Department of Soil and Groundwater Quality

Topic: Geophysics of the marine environment

\section{INTRODUCTION}

Sandy continental shelves and adjacent tidal basins are dynamic on different spatial and temporal scales. Sandy sea beds of shallow seas are characterized by marine bedforms of various size, such as sand banks, long bed waves, sand waves and megaripples. Tidal basins are dominated by migrating tidal channels and eroding and accreting tidal flats. Each of these bedforms and depositional environments evolves in response to extreme events and every-day processes of different energy and frequency. These dynamics may affect navigation safety, especially where drafts of vessels are similar to water depths. In areas with such critical depths for shipping, such as parts of the southern North Sea, nautical maps must be kept up-to-date, and the changing sea bed needs to be re-surveyed at an appropriate frequency. Other applications of up-to-date maps and bathymetric monitoring series are impact studies for planned offshore engineering projects such as wind farms, habitat mapping, evaluations of archaeological value and preservation, and assessments of system resilience to climate change. As of yet, no guidelines for the validation and optimization of re-survey policies exist. Guidelines on monitoring location and frequency must be a function of (a) relevance of bathymetric observations to various types of end use and (b) observed large-scale dynamics on different time scales.

Previous empirical studies of seabed morphodynamics have focused on the analysis of marine bedforms of small sites with specific local conditions [e.g. Duffy and Hughes-Clarke, 2005; Knaapen, 2005; Buijsman and Ridderinkhof, 2008; Van Dijk et al., 2008; Dorst et al., 2011]. Recently, a regional-scale study of morphodynamics was carried out for the German coastal zone [Winter, 2011]. Thus far, no such study exists for the Netherlands Continental Shelf (NCS). Such a study would provide an overview of the spatial variation in seabed dynamics, which would increase our insight and understanding of the processes of bed evolution.

Multiple datasets (time series) of digital bathymetric data, which are required for the study of sea-bed morphodynamics, have become sufficiently available for the NCS only recently. As monitoring techniques have improved, the horizontal precision of the resulting data has become increasingly 
suited to the detailed and quantitative analyses of bed changes and bedform mobility. In the analysis of the NCS, lessons can be learned from approaches used in quantifying bed dynamics and sediment transport in the Wadden Sea.

The aim of this paper is to present the vertical sea-bed dynamics of the Netherlands Continental Shelf and the Dutch part of the Wadden Sea, based on a quantitative analysis at a $25 \times 25$ m (NCS) and 20 x $20 \mathrm{~m}$ (Wadden Sea) resolution. Detailed analyses of selected locations serve to describe the local morphology and dynamics of individual bedforms.

\section{DATA AND METHODS}

\section{Bathymetric data}

For the NCS, all data from the digital Bathymetric Archive System (BAS) of the Hydrographic Service of the Royal Netherlands Navy below the $10 \mathrm{~m}$ isobath were used. This database includes data collected by Rijkswaterstaat for the coastal zone. Digital data in BAS comprise both single-beam echo soundings (SBES) and multi-beam echo soundings (MBES). Digital data for the Wadden Sea include SBES of subtidal areas (older ones digitized from their original analog format) and laser altimetry for intertidal and supratidal areas.

It is not possible to generate a single time series for the entire study area. The overlap of surveys creates time series of various spatial extents and covering different periods. For the NCS, most time series comprise no more than two or three datasets; at few locations, time series of more than five datasets exist. For locations with only a single digital bathymetric record, time series were created by digitizing historical echo soundings from plotted or hand-written fair sheets. For the Wadden Sea, partial surveys have been conducted by Rijkswaterstaat in such a way that the entire tidal basin is surveyed every five to six years. The data density and precision (horizontal positioning and echosounding beams) differ per method and in time. The analyzed digital datasets for the NCS were acquired between the late 1980s and J une 2010, those for the Wadden Sea between 1985 and 2006. Digitized fair sheets date from before those time periods, but are not available for the eastern Wadden Sea.

Digital Elevation Models (DEMs) were created from the NCS bathymetric data by interpolating to a 25 $\times 25 \mathrm{~m}$ grid, using the Inverse Distance Weighting algorithm with a search radius of $100 \mathrm{~m}$. This $25 \mathrm{~m}$ resolution was chosen to still represent sand waves (hundreds of meters in length) well and to minimize the introduction of interpolation artefacts of single beam echo soundings in track lines. The interpolation technique used to create grids from the Wadden Sea data is DIGIPOL, software that incorporates the orientation of (morphological) features in the original $x-y-z$ points as part of an iterative linear interpolation.

\section{Analysis of vertical dynamic trends}

In analyzing bathymetric datasets, we are confronted with overlap issues, different numbers of surveys, different periods of acquisition, and different methodologies and associated uncertainties. Therefore, it is insufficient to use average values of bed-elevation change or create simple erosionsedimentation grids.

For the quantitative analysis of vertical dynamic trends (m/yr) for each grid node on the NCS, we developed a fully automated linear regression of all bed elevations in the stacked time series per node. Visual inspection of the nodal bed elevations in time has shown that linear regression is justified within in the periods that are covered by the time series. Because the correction for tides and ship movements provided differences between surveys that are larger than the (natural) vertical dynamics, we corrected for this discrepancy by subtracting the averaged vertical dynamics for each specific stacked combination of surveys from the vertical dynamics at each node. 
For the Wadden Sea, we used all values for each node to calculate the difference between the most recent grid (i.e. the 2006 bathymetry) and the minimum values for the period 1927-2006. The volume bounded by these grids provides a measure of the century-scale net sediment dynamics within the tidal basin.

\section{Geometry and mobility of individual bedforms}

Detailed morphological and dynamic analyses of individual sand waves and long bed waves were conducted only for the NCS. As part of these analyses, the bathymetric signal was separated into bedform types of different spatial scales by truncating a Fourier approximation at certain frequencies [cf. Van Dijk et al., 2008]. From the smoothed bedform signal, locations of crest, trough and inflection points were then determined in a semi-automated way, from which the geometry and dynamics of individual bedforms were calculated.

\section{RESULTS}

\section{Vertical dynamic trends on the NCS}

The quantified vertical nodal dynamic trends for the NCS (Figure 1) provide an overview of regions of contrasting dynamics. In general, the coastal zone is more dynamic than the continental shelf. The highly dynamic coastal zone includes estuaries, tidal inlets with ebb-tidal deltas, tidal channels and breaker bars. Dynamic trends in these environments typically range between absolute values of 0.1 and $0.35 \mathrm{~m} / \mathrm{yr}$, with extremes up to $1.5 \mathrm{~m} / \mathrm{yr}$. In areas strongly influenced by man, annual changes may even be greater.

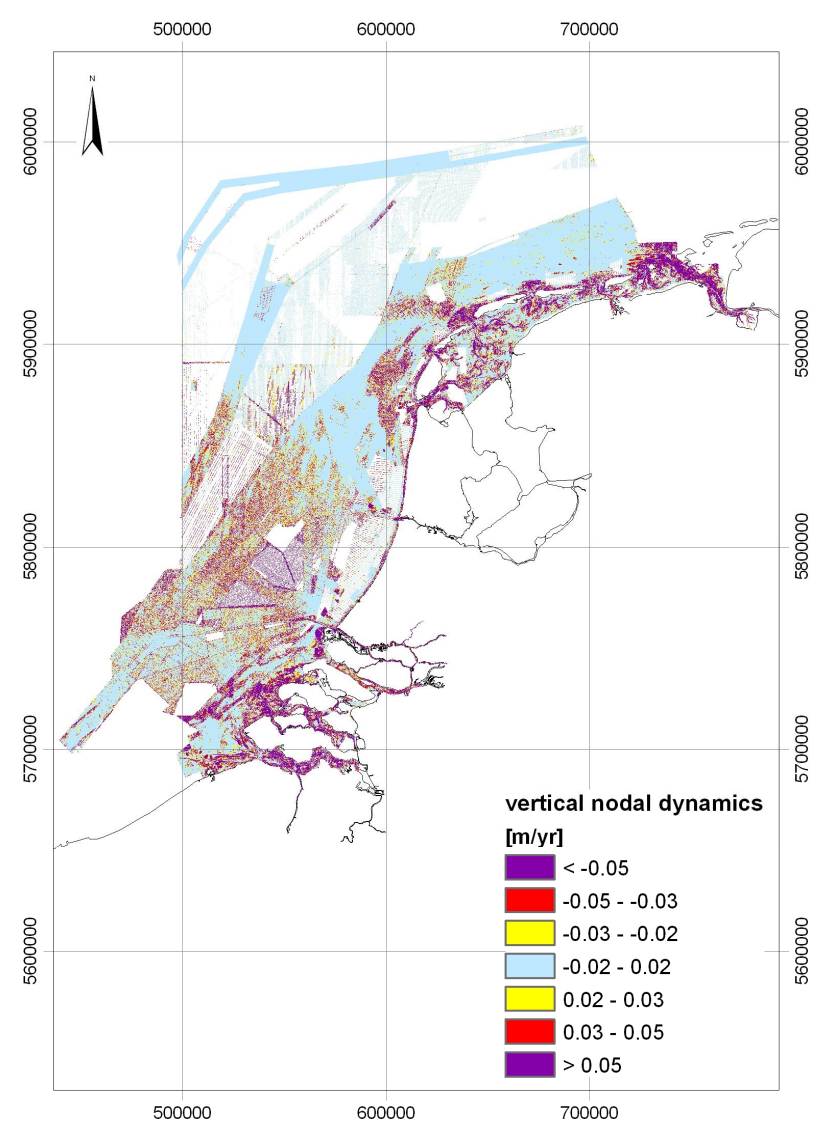

Figure 1: Vertical nodal dynamic trends of the NCS (absolute values). Vertical dynamic trends are simplified into classes of absolute values in order to amplify the dynamic contrasts. Thus, this map does not display the full range of dynamic trends, which apart from extremes may range between -0.35 and $0.35 \mathrm{~m} / \mathrm{yr}$ degradation and aggradation. 
Areas of moderate dynamics are prevalent farther offshore on mostly sandy parts of the NCS, where rhythmic bedforms are present. Here, values typically range between -0.1 to $0.1 \mathrm{~m} / \mathrm{yr}$, with extremes of $0.3 \mathrm{~m} / \mathrm{yr}$ in fields of rapidly migrating sand waves. The appearance of bedform patterns in the vertical dynamics map indicates that the measure of vertical dynamics is controlled by the migration and/or growth of individual bedforms. Examples are the sand-wave field west of Texel, a long-bedwave field north of Texel and Vlieland, and the tidal ridges $75 \mathrm{~km}$ offshore Texel.

Areas of very low sea-bed dynamics (around $0 \mathrm{~m} / \mathrm{yr}$; light blue in Figure 1 ) occur mostly in parts of the NCS where rhythmic bedforms are absent. The largest areas of low dynamics occur far offshore, in the deepest and parts of the NCS. Smaller stable areas are present north of the Wadden islands, where shoreface-connected ridges show little mobility, various patches offshore the coast and at the large ebb-tidal delta of the Western Scheldt.

\section{Vertical dynamic trends in the Wadden Sea}

The two surfaces formed by all minimum and 2006 values bracket the active layer, which has a volume of more than $1.7 \times 10^{9} \mathrm{~m}^{3}$ (Figure 2). For shorter periods within this time frame, subsets of the bathymetric database form the basis for various derivative grids that allow us to constrain the net sediment dynamics and its variability on a multi-decadal time scale. The value of annual net sediment dynamics is dependent on the time period considered. It is as high as $53 \times 10^{6} \mathrm{~m}^{3}$ for 1999-2006 but less than $3 \times 10^{6} \mathrm{~m}^{3}$ for the entire Holocene. In terms of net sedimentation rates, these two values translate to 1.9 and $0.1 \mathrm{~mm} / \mathrm{yr}$, respectively.

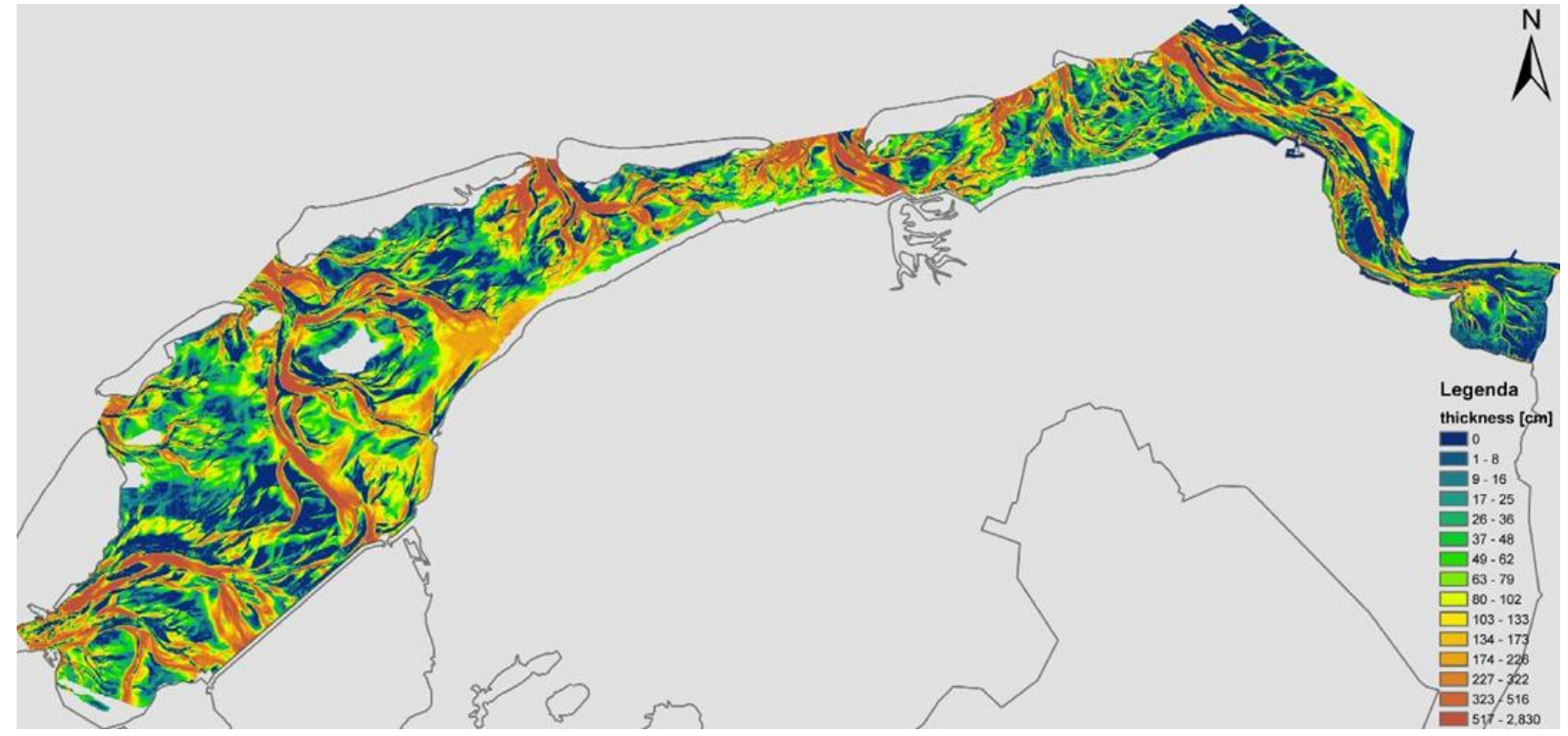

Figure 2: Grid showing the difference between minimum and present depth values for the period 1927-2006. Changes are the largest around the main channels, the main mechanism for the internal redistribution of sediments. The watersheds are clearly recognizable, as these areas have hardly been reworked.

\section{Bedform size and mobility}

Detailed analyses of individual bedforms provide more information on the geometry, mobility and morphodynamics of bedforms. The sand wave field west of Texel comprises sand waves with an average wavelength of $345 \mathrm{~m}$ and an average wave height of $1.4 \mathrm{~m}$. With an average sand wave migration rate of 16 to $19 \mathrm{~m} / \mathrm{yr}$ to the northeast, this area is exceptionally dynamic compared to other sand wave fields on the NCS, where migration rates are mostly less than $5 \mathrm{~m} / \mathrm{yr}$ [Van Dijk et al., 2011]. 
The long bed waves north of Texel have an average wavelength of $1125 \mathrm{~m}$ and an average wave height of $3.4 \mathrm{~m}$. Net migration rates, based on 3 surveys between 1990 and 2009 (Figure 3), range from 10.5 to $18.4 \mathrm{~m} / \mathrm{yr}$, with an average of $12.4 \mathrm{~m} / \mathrm{yr}$ to the northeast.

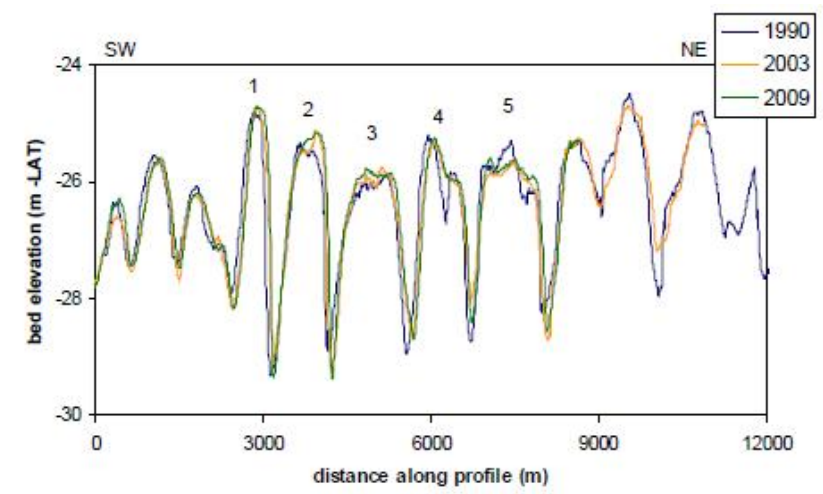

Figure 3: Profiles (SE to NW) of long bed waves north of Texel and Vlieland from the 1990, 2003 and 2009 datasets.

The average wavelength of the shoreface-connected ridges north of Wadden islands is $4614 \mathrm{~m}$ and the average height is $4.3 \mathrm{~m}$. Changes in dimensions are negligible and the average migration rate is $1.0 \mathrm{~m} / \mathrm{yr}$ to the southwest (Figure 4).

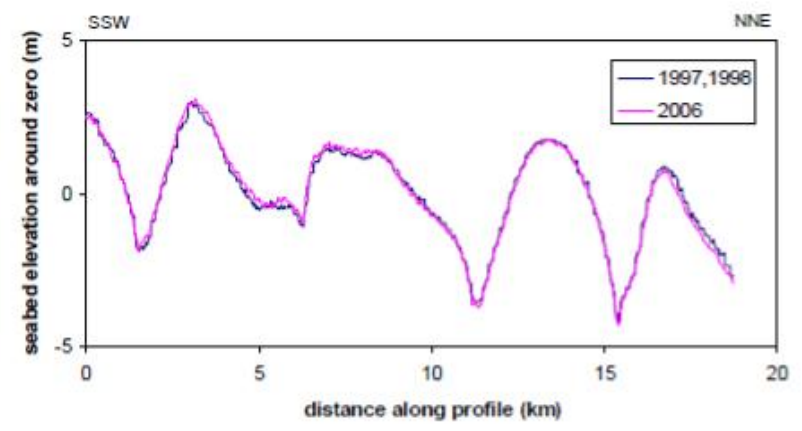

Figure 4: Profiles (SSW to NNE) of the shoreface-connected ridges north of the Wadden islands indicate that these bedforms are stable on a decadal scale.

\section{DISCUSSION}

A study of vertical bed level changes of a wide coastal zone of the German Continental Shelf, recently completed by Winter [2011], shows an overall pattern of highly dynamic estuaries and tidal inlets and much less dynamic offshore areas that is in good agreement with our findings of the NCS and the Wadden Sea. When focusing on smaller-scale features, extreme differences can be observed. Shoreface-connected ridges offshore a German Wadden island, for example, are two orders of magnitude more dynamic than their counterparts offshore the Dutch Wadden islands [Antia, 1996].

Observed differences in the dynamics of similar bedforms may be related to grain-size effects (maps of median grain size and bed dynamics correspond well); current velocity (maps of sediment-transport potential agree with migration rates of sand waves and long bed waves), and bedform-size differences (the German shoreface-connected ridges are shorter and lower than the adjacent Dutch ones).

Vertical dynamic trends are sensitive to data-quality issues, such as data density and precision. Lowresolution data, especially from older measurements, may underestimate bedform amplitudes and even high-resolution state-of-the-art measurements are associated with vertical uncertainties of several centimeters to a decimeter. The shorter the time series under consideration, the more influential the errors of such data limitations. Therefore, comparisons of analog legacy data with modern digital bathymetries should only be attempted when the time period covered by these datasets is on the order of decades or longer. Aside from intercomparing individual survey results, extreme values derived from complete monitoring series may be used to assess and constrain sediment dynamics. 


\section{APPLICATIONS}

Analyses of sea-bed dynamics can be used to validate and to optimize hydrographic survey policies. Grounding dangers for shipping can be determined from shipping intensity, predicted water depth and the probability of unknown objects at the bed. They also provide constraints on sea-bed stability, needed to budget offshore engineering projects, such as the construction and maintenance of offshore wind farms, cables and pipelines. The chance of exposed foundations and freespans must be minimized. Sea-bed dynamics are also relevant for habitat studies, with benthic species and assemblages being sensitive to temporal change. Finally, knowledge on the morphodynamics of tidal channels and sand banks is crucial in understanding the preservation potential and exposure risk of archaeological remnants such as wrecks and Mesolithic paleolandscapes.

Information on net sediment dynamics as derived from sea-bed monitoring is instrumental in assessing the reliance of sedimentary systems to effects of climate change, particularly relative sealevel rise. Bathymetric time series have demonstrated that the internal sediment dynamics of the Wadden Sea is perfectly capable of neutralizing both man-made and sea-level-driven increases in accommodation space.

\section{CONCLUSIONS}

Vertical nodal dynamic trends of the Netherlands Continental Shelf and Wadden Sea can be determined using different protocols, developed to maximize the usefulness of the underlying datasets and to minimize the effect of error.

Observed vertical trends in sea-bed dynamics are crucial in optimizing re-survey policies, marine spatial planning, assessments of archeological potential and studying the effects of climate change.

\section{ACKNOWLEDGEMENTS}

All data were provided by the Hydrographic Office, Royal Netherlands Navy, and Rijkswaterstaat, Ministry of Infra Structure and the Environment. Part of this work was financed by the Ministry of Defense.

\section{REFERENCES}

Antia, E.E. "Rates and patterns of migration of shoreface-connected ridges along the southern North Sea coast." Journal of Coastal Research 12 (1996): 38-46.

Buijsman, M.C. and H. Ridderinkhof. "Long-term evolution of sand waves in the Marsdiep inlet, II: relation to hydrodynamics." Continental Shelf Research 28 (2008): 1202-1215.

Dorst, L.L., P.C. Roos and S.J.M.H. Hulscher. "Spatial differences in sand wave dynamics between the Amsterdam and the Rotterdam region in the Southern North Sea." Continental Shelf Research 31 (2011): 1096-1105.

Duffy, G.P. and J.E. Hughes-Clarke. Application of spatial cross correlation to detection of migration of submarine sand dunes." J. of Geophysical Res 110 (2005): F04S12, doi:10.1029/2004J F000192.

Knaapen, M.A.F. "Sandwave migration predictor based on shape information." J ournal of Geophysical Research, 110 (2005): F04S11, doi:10.1029/2004J F000195

Van Dijk, T.A.G.P., R.C. Lindenbergh and P.J.P. Egberts. "Separating bathymetric data representing multi-scale rhythmic bedforms: a geostatistical and spectral method compared." Journal of Geophysical Research 113 (2008): F04017, doi:10.1029/2007J F000950.

Van Dijk, T.A.G.P., C. Van der Tak, W.P. De Boer, M.H.P. Kleuskens, P.J . Doornenbal, R.P. Noorlandt, and V.C. Marges. "The scientific validation of the hydrographic survey policy of the Netherlands Hydrographic Office, Royal Netherlands Navy." Deltares report, 2011, 165 pp.

Winter, C. "Macro scale morphodynamics of the German North Sea coast." J ournal of Coastal Research SI 64 (2011): 706 - 710. 


\section{BIOGRAPHIES}

Thaiënne VAN DIJK studied Physical Geography at the University of Amsterdam, Netherlands, and obtained her Ph.D. at Keele University, UK, in 2001. She worked as a Marine Geologist at TNO Geological Survey of the Netherlands on Quaternary mapping and habitat mapping projects in the North Sea. VAN DIJK now is a specialist in the morphodynamics and geology of sea beds. She leads applied research projects at Deltares and is a lecturer at the University of Twente in these themes.

Sytze VAN HETEREN is a coastal and marine geologist. He received his Ph.D. at Boston University. After completing a post-doc on sea-level change at the Vrije Universiteit Amsterdam, he joined the Geological Survey to coordinate and work on various national and international research projects on coastal behavior, sea-bed habitats and geological databases.

\section{CONTACT DETAILS}

Thaiënne VAN DIJK

Deltares

Dept. of Applied Geology and Geophysics

P.O. Box 85467

3508 AL Utrecht

NETHERLANDS

Tel.: + 31883357798

Fax.: +31883357856

E-mail: thaienne.vandijk@deltares.nl

Website: www.deltares.nl

Linkedln account: Thaienne A.G.P. van Dijk 